\title{
Polypoid mucosal prolapse in a pelvic ileal reservoir
}

J M Blazeby, P Durdey, B F Warren

\begin{abstract}
A case of a patient who developed a polypoid area of mucosal prolapse three and $a$ half years after having an ileoanal pouch for ulcerative colitis is presented. This seems to be the first published report. This new manifestation of mucosal prolapse in a pelvic ileal reservoir underlines that the pouch as a neorectum is subject to disorders familiar in the rectum.

(Gut 1994; 35: 1668-1669)
\end{abstract}

\section{Case report}

A 35 year old man with a nine year history of ulcerative colitis was admitted in June 1987 with increasing rectal bleeding and diarrhoea. This failed to settle with conservative medical treatment. He therefore underwent a proctocolectomy and construction of a W ileoanal pouch with a covering loop ileostomy. ${ }^{1} \mathrm{He}$ made an uneventful postoperative recovery. Four months later his ileostomy was closed. Apart from removal of a suture from his ileostomy site, he remained well for the next three years. In January 1992, three and half

University Department of Surgery

J M Blazeby

P Durdey

and University

Department of

Pathology and

Microbiology

B F Warren

Bristol Royal Infirmary, Bristol

Correspondence to: Dr B F Warren, Department of Pathology and

of Pathology and Infirmary, Bristol BS2 8HW.

Accepted for publication 11 March 1994

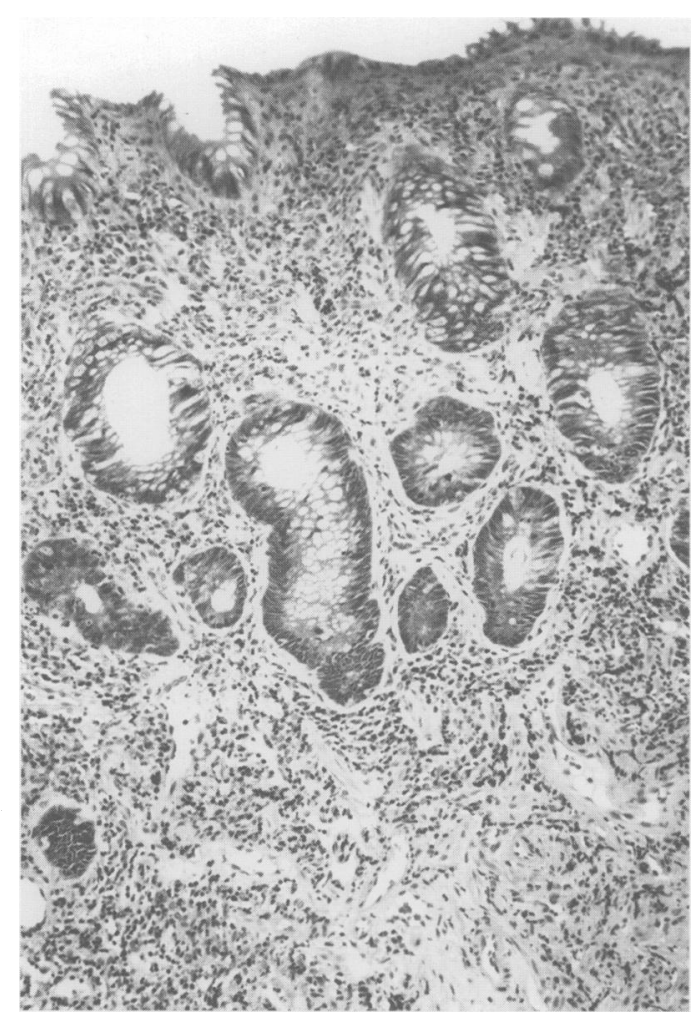

Pouch polyp biopsy specimen (haematoxylin and eosin $\times 156)$. This shows intercrypt smooth muscle fibres, a disrupted and thickened muscularis mucosae, and diamond shaped crypts. There is mild diffuse chronic inflammation in the lamina propria. years after his surgery he presented with vague lower abdominal pain, increasing rectal bleeding, and increased bowel frequency of eight to 10 times per day with straining on each occasion. Proctoscopy showed a polypoidal lesion arising from the anterior wall of his pouch. A flexible sigmoidoscopy showed an anterior pouch mucosal prolapse. Histological examination of this polypoid lesion showed muscularised flat (non-villous) pouch mucosa with disruption and thickening of the muscularis mucosae (Figure). There was no evidence of suture material. These features are typical of mucosal prolapse. The biopsy specimens from the remainder of the pouch were normal flat pouch with no features of pouchitis. Under a general anaesthetic the polypoid mucosal prolapse was banded. Since that time he has remained asymptomatic and is continuing under annual pouch surveillance.

\section{Discussion}

This is the first recorded case of a polypoid mucosal prolapse in a pelvic ileal reservoir. Anterior mucosal prolapse has been reported previously in W pouches and has been termed anterior strip pouchitis. ${ }^{2-4}$ Both anterior strip pouchitis and this case of polypoid mucosal prolapse in a pouch share identical histological features. This is not surprising because the protean clinical manifestations of mucosal prolapse in the colorectum have similar histological features. ${ }^{5}$ These are characteristically thickening and disruption of the muscularis mucosae and entry of smooth muscle fibres into the lamina propria along with diamond shaped crypts and mucosal elastosis. $^{6-9}$ Conditions included within this unifying concept of mucosal prolapse are solitary rectal ulcer syndrome, polypoid mucosal prolapse, inflammatory cloacogenic polyp, and inflammatory cap polyposis. ${ }^{10}$ It is likely that there should be several clinical and endoscopic manifestations of mucosal prolapse within a pouch (neorectum) and that they should have similar histological features. Another cause of muscularis mucosal disruption within a pouch biopsy specimen is seen in tissues from pouch suture lines, which this specimen was not.

This case illustrates that not all pouch symptoms result from pouchitis, and that not all cases of endoscopic inflammation within the pouch result from pouchitis. It also highlights the need for biopsy (away from suture lines) to make histological conformation of the endoscopic diagnosis. In a pouch constructed for familial adenomatous polyposis, it would be important to distinguish a case such as this 
from an adenoma. ${ }^{11}$ Longterm consequences of pelvic ileal reservoir construction remain unknown and pathological changes need to be recorded as they occur. ${ }^{11} 12$ This case is a new manifestation of mucosal prolapse in the pouch and is identical to polypoid mucosal prolapse in the rectum.

1 Nicholls RJ, Pezim ME. Restorative proctocolectomy with ileal reservoir for ulcerative colitis and familial adenomatous polyposis: a comparison of three reservoir designs. Br F Surg 1985; 72: 470-4

2 Shepherd NA, Jass JR, Duval I, Moskowitz RL, Nicholls RJ, Morson BC. Restorative proctocolectomy with ileal reservoir: pathological and histochemical study of mucosal biopsy specimens. F Clin Pathol 1987; 40: 601-7.

3 Warren BF, Shepherd NA. Pouch pathology. In: Nicholls RJ, Mortensen NM, Bartolo DCC, eds. Restorative proctocolectomy. London: Blackwell Scientific, 1993: 147-62.

4 Warren BF, Bartolo DCC, Bradfield JWB. Pouchitis or prolapse? F Pathol 1990; 161: 355A.
5 Du Boulay CEH, Fairbrother J, Isaacson PG. Mucosal prolapse syndrome - a unifying concept for solitary ulcer syndrome and related disorders. $\mathcal{f}$ Clin Pathol 1983; 36: 1264-8.

6 Bartolo DCC, Warren BF. Refractory solitary rectal ulcer syndrome. In: Dobrilla $\mathrm{G}$, Bardhan $\mathrm{KD}$, Steele A, eds. Cortina International, Raven Press, 1991: 169-80.

7 Madigan MR, Morson BC. Solitary ulcer of the rectum. Gut 1989; 10: 871-88.

8 Warren BF, Dankwa EK, Davies JD. Diamond shaped crypts and mucosal elastin: helpful diagnostic features in biopsies of rectal prolapse. Histopathology 1990; 17: biopsies of rectal prolapse. Histopathology 1990; 17:

9 Warren BF, Davies JD. Cloacogenic polyps - clinical features and pathological features [letter]. Histopathology 1989; 15: 103 .

10 Campbell AP, Cobb CA, Chapman RWG, Kettlewell M, Hoang P, Haot BJ, et al. Cap polyposis, an unusual cause of diarrhoea. Gut 1993; 34: 562-4.

11 Shepherd NA. The pelvic ileal reservoir: apocalypse later? $B M 7$ 1990; 301: 806-7.

12 Warren BF, Shepherd NA. The role of pathology in pelvic ileal reservoir surgery. Int $\mathcal{F}$ of Colorectal Dis 1992; 7: 68-72. 